\title{
Investigation of magnesium oxychloride cement at the initial hardening stage
}

\author{
Galina Averina, ${ }^{1, *}$, Tamara Chernykh ${ }^{1}$, Aleksandr Orlov $^{1}$, and Lyudmila Kramar $^{1}$ \\ ${ }^{1}$ South Ural State University (National Research University), 454000 Chelyabinsk, Russia
}

\begin{abstract}
The paper investigates the process of variation of magnesium oxychloride cement deformations at the initial hardening stage depending on the activity of magnesium oxide powder which is determined by the parameters of the source material burning. Investigation is focused on magnesium cements obtained from pure magnesium hydroxide. Source materials were burnt at various temperatures with the purpose to obtain magnesium oxide powder with different activity. Regular content of hydrated phases was determined in hardened magnesium cement prepared on the basis of binders with different activity. The study reveals the influence of magnesium oxide powder activity on the process of deformation occurrence in hardened magnesium cement and its tendency to crack formation.
\end{abstract}

\section{Introduction}

This research is aimed at finding the connection between the magnesium cement activity and its deformation behavior in the hardening process and active hydration period.

To date, the production of building materials based on magnesium cement is cut down because of insufficient awareness on the processes of its hydration and hardening, and because of connection of these processes with phase composition and properties of the obtained hardened cement.

It is known that up to date the effect of crystallite size in magnesium oxide (the activity of the cement) on the peculiarities of hydration and structure formation in hardened magnesium cement has not been determined, as well as the influence of the obtained hardened cement structure on its deformation behavior and crack formation tendency. Investigation of these processes will enable to determine the optimum conditions for obtaining magnesium cements in production environment and avoid failure of structures made from such cements because of uncontrolled expansion deformations.

Due to investigating hydration of magnesium cement the peculiarities of interaction between magnesium oxide and water solution of magnesium chloride and magnesium sulphate were determined [1-7].

Magnesium oxide powders mixed with solutions of magnesium chloride salts possess the highest strength properties and are most often used in production of construction products based on magnesium cement.

*Corresponding author: averinagf93@gmail.com 
Many authors in their previous research showed that hardening of magnesium oxychloride cement results in formation of a hardened cement paste consisting of the mix of $\mathrm{Mg}(\mathrm{OH})_{2}$ and magnesium chloride hydroxides of type $\mathrm{xMgO} \times \mathrm{MgCl}_{2} \times \mathrm{yH}_{2} \mathrm{O}$. According to different authors, "x" varies between 1 and 10, and " $y$ " - between 5 and 21 [1-4]. It was found that hardened magnesium chloride paste of natural hardening is usually formed by hydroxide, chloride pentahydroxide and chloride trihydroxide of magnesium, their different quantitative content having certain effect on the material properties [5-8].

Besides, the influence of activator density on the phase composition of hardened magnesium chloride paste was determined. Magnesium chloride pentahydroxide is synthesized with the average concentration of $\mathrm{MgCl}_{2}$ and with the solution density of 1.20 $\mathrm{g} / \mathrm{cm}^{3}$ and higher. Mixtures of magnesium hydroxide and magnesium chloride pentahydroxide can be equilibrium products of magnesium chloride hardening in this environment. With higher concentration of activator the equilibrium phases are mostly represented by magnesium chloride pentahydroxide with insignificant content of hydroxide and chloride trihydroxide of magnesium. With low contents of $\mathrm{MgCl}_{2}$ (lower than 1.80 $\mathrm{g} / \mathrm{cm}^{3}$ ) it is mostly magnesium hydroxide that is synthesized in the system. Increase in activator concentration leads to higher stability of chloride pentahydroxide phase, whereas magnesium hydroxide is either absent in such systems or is synthesized in small amount [912].

Burning of bulk magnesium raw material with non-uniform grain size distribution can result in instability of composition of the cement produced from it because of both overburn and underburn in the cement powder [13]. Underburn is represented by magnesium oxide crystals with high activity, which is characterized by their quick reaction with chlorides. By overburn are meant magnesium oxide crystals enlarged up to the size of $50 \mathrm{~nm}$. Even small amount of overburn containing in the powder causes internal expansion deformations in hardened magnesium paste as a result of their hydration accompanied by increase of volume by 2.5 times at later hardening stages [14].

In case of using the waste of fire protection or mining industries as raw material for cement production, one of the reasons for such deformations in hardened magnesium cement is high content of calcium carbonate in the source rock [15]. According to GOST 1216-87, the calcium oxide admixture which is synthesized while decomposition of dolomite and calcite is considered adverse for magnesium cement and shall be limited up to $5 \%$ [16]. Negative effect of calcium oxide on the quality of magnesium cement is confirmed by many scientists, both national and foreign [17-20].

\section{Materials and Methods of Research}

Raw material for producing cements was pure magnesium hydroxide $\operatorname{Mg}(\mathrm{OH})_{2}$. Pure magnesium chloride (bishofite $\mathrm{MgCl} 26 \mathrm{H} 2 \mathrm{O}$ ) in the form of water solution with the density of $1.2 \mathrm{~g} / \mathrm{m}^{3}$ was used as activator and taken in the sufficient amount to provide standard consistency [16]. To find the dependences of deformations occurring in hardened magnesium oxychloride cement on the activity of magnesium oxide, five types of cements were prepared and burnt at the temperature of 400, 450, 700 and $900{ }^{\circ} \mathrm{C}$ for 1 hour in the laboratory batch furnace PKL-1,2.

Raw materials and the samples of hardened magnesium cement were investigated with the help of derivatography and other methods [16, 21-23]. Thermal analysis of minerals was performed using Luxx STA 409 derivatograph (Netsch, Germany).

Linear deformations in the material while hardening were studied using shrinkage measuring devices Schwindmessgerät Typ B in accordance with GOST 24544-81 and DIN $52450[21,22]$. The samples were produced in stay-in-place forms. The moment of mixing the cement with activator was taken as a starting point for measuring deformations. 
Soundness of cement while hardening was measured using the technique described in TU 5744-001-60779432-2009 [23].

The loss of activator while hardening was defined in percentage of the difference in masses of mixed cement paste and hardened magnesium cement.

\section{Results}

Preliminary soundness tests were performed using sample cement formed into pats. The samples produced with the use of magnesium oxide powders and burnt at the temperature of 400 and $450{ }^{\circ} \mathrm{C}$ developed cobweb-like through cracks within the first hour of hardening. The samples obtained on the basis of magnesium oxide and burnt at 700 and $900{ }^{\circ} \mathrm{C}$ preserved their integrity after all tests.

The final setting of the samples from magnesium oxide powder burnt at 400 and $450{ }^{\circ} \mathrm{C}$ was 20 and 27 minutes respectively; for samples burnt at 700 and $900{ }^{\circ} \mathrm{C}-65$ minutes.

The results of measuring activator loss while hardening are given in Table 1.

Table 1. Weight loss of hardened samples at the age of 1 day.

\begin{tabular}{|c|c|}
\hline Burning temperature, ${ }^{\mathbf{0}} \mathbf{C}$ & Weight loss, $\%$ \\
\hline 400 & 4.5 \\
\hline 450 & 6 \\
\hline 700 & 8 \\
\hline 900 & 9 \\
\hline
\end{tabular}

Deformations were measured every minute within the first hour after mixing, then measurements were taken once in two hours. The period of continuous measurements was 14 days. The graphs of deformation varied every two hours are presented in Figures 1-4. Measuring unit for deformation was accepted $\mathrm{mm} / \mathrm{m}$.

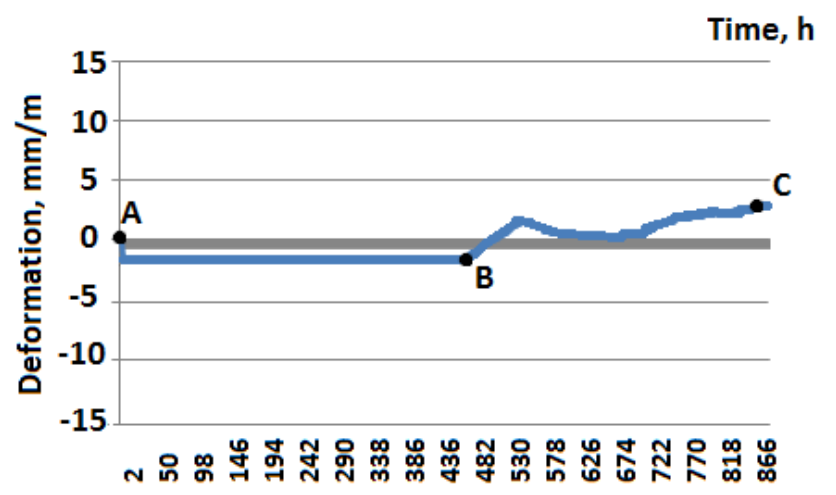

Fig. 1. Graph of deformation variations in samples produced from magnesium oxide powder and burnt at $400^{\circ} \mathrm{C}$. 
Time, $\mathbf{h}$

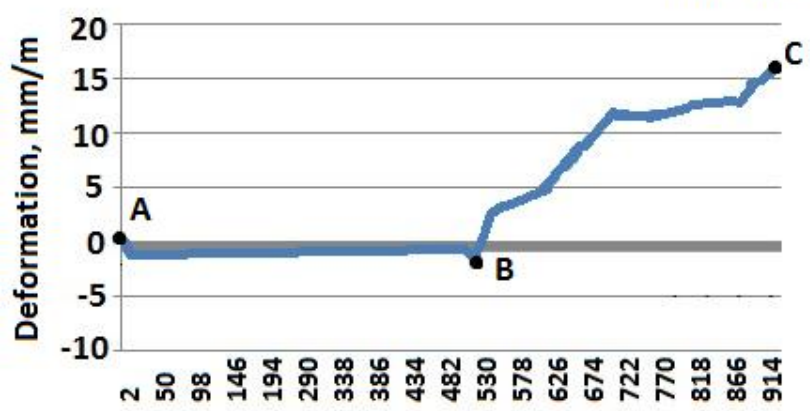

Fig. 2. Graph of deformation variations in samples produced from magnesium oxide powder and burnt at $450{ }^{\circ} \mathrm{C}$.

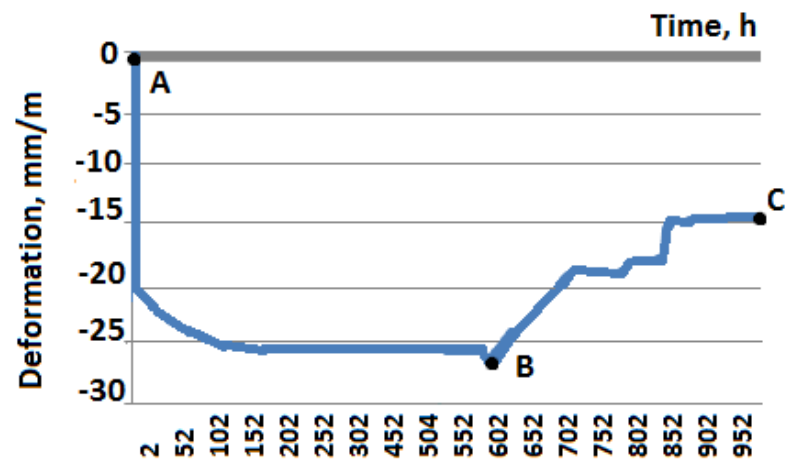

Fig. 3. Graph of deformation variations in samples produced from magnesium oxide powder and burnt at $700{ }^{\circ} \mathrm{C}$.

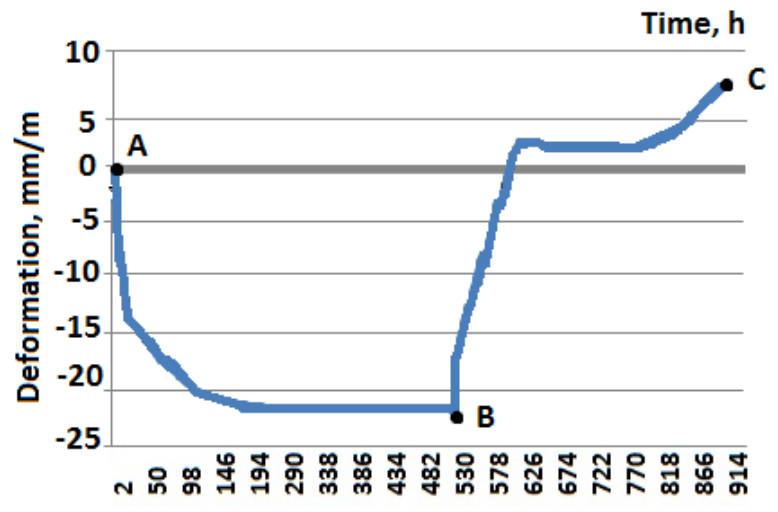

Fig. 4. Graph of deformation variations in samples produced from magnesium oxide powder and burnt at $900{ }^{\circ} \mathrm{C}$.

The graphs demonstrate that deformations in all types of cements have similar behavior, but differ in value and time they originally occur. The highest activity is observed in magnesium oxide obtained at the lowest burning temperature $\left(400{ }^{\circ} \mathrm{C}\right)$, and the magnesium oxide burnt at the highest temperature $\left(900^{\circ} \mathrm{C}\right)$ shows the lowest activity. Based on this fact 
one can conclude that the value and duration of initial setting (interval A-B) increase as the powder activity reduces. After initial setting, all samples experience two-stage expansion deformation (interval B-C). Duration of this process and the value of deformations also increase as the powder activity reduces.

Thermal analysis was performed to determine the main phases' composition and analyze their quantitative content in the samples. Using the data of derivatograms the summary tables were built with quantitative content of phases in samples measured in the first day (Table 2) and in the $14^{\text {th }}$ day of hardening (Table 3 ).

Table 2. Phase composition of the samples in the first day of hardening.

\begin{tabular}{|c|c|c|c|}
\hline $\begin{array}{c}\text { Burning } \\
\text { temperature, } \\
{ }^{\mathbf{C}} \mathbf{C}\end{array}$ & $\begin{array}{c}\mathbf{M g}(\mathbf{O H})_{\mathbf{2}}, \\
\mathbf{\%}\end{array}$ & $\begin{array}{c}\mathbf{3} \mathrm{MgO} \times \mathbf{M g C l}_{\mathbf{2}} \times \mathbf{8 H}_{\mathbf{2}} \mathbf{O}, \\
\mathbf{\%}\end{array}$ & $\begin{array}{c}\mathbf{5 M g O} \times \mathbf{M g C l}_{\mathbf{2}} \times \mathbf{1 3 H}_{\mathbf{2}} \mathbf{O}, \\
\mathbf{\%}\end{array}$ \\
\hline 400 & 26 & 25.7 & 41 \\
\hline 900 & 26 & 12.5 & 52 \\
\hline
\end{tabular}

Table 3. Phase composition of the samples in the $14 \mathrm{t}^{\mathrm{h}}$ day of hardening.

\begin{tabular}{|c|c|c|c|}
\hline $\begin{array}{c}\text { Burning } \\
\text { temperature, } \\
\mathbf{}^{\mathbf{C}}\end{array}$ & $\begin{array}{c}\mathbf{M g}(\mathbf{O H})_{\mathbf{2}}, \\
\mathbf{\%}\end{array}$ & $\begin{array}{c}\mathbf{3} \mathbf{M g O} \times \mathbf{M g C l}_{\mathbf{2}} \times \mathbf{8 H}_{\mathbf{2}} \mathbf{O}, \\
\mathbf{\%}\end{array}$ & $\begin{array}{c}\mathbf{5} \mathbf{M g O} \times \mathbf{M g C l}_{\mathbf{2}} \times \mathbf{1 3 H}_{\mathbf{2}} \mathbf{O}, \\
\mathbf{\%}\end{array}$ \\
\hline 400 & 25 & 22 & 53 \\
\hline 450 & 20 & 21 & 59 \\
\hline 700 & 14 & 18 & 68 \\
\hline 900 & 13 & 15.7 & 70 \\
\hline
\end{tabular}

The following conclusions can be made based on these data. Hardened magnesium cement paste obtained from magnesium oxide and burnt at low temperature has the highest content of magnesium hydroxide at the final hardening stages. With the increase of burning temperature the presence of magnesium hydroxide phase in the hardened magnesium cement paste decreases due to higher quantity of magnesium chloride pentahydroxide phase. Content of magnesium chloride trihydroxide is almost the same for all samples and shows slight decrease with the growth of burning temperature.

Hydration processes in cements produced from magnesium oxide powders with different activity have similar behavior and differ only in their rate. High activity magnesium oxide obtained by low temperature burning is characterized by quick reaction with chlorides, quick setting and hardening due to high growth rate of magnesium chloride hydroxide crystals. As the cement activity reduces with longer crystallization process, higher content of magnesium chloride pentahydroxide is synthesized.

The highest shrinkage deformations are observed in magnesium oxide with lower activity at early age. Table 1 shows that weight loss in samples produced from powders burnt at low temperature is lower than in those produced from powders burnt at high temperature. Thus, almost no deformations related to contraction shrinkage are observed in high activity cements due to their high setting rate.

With the increase of burning temperature, the percentage of expansion deformations in the obtained cement grows, since a higher amount of free magnesium oxide is synthesized and reacts with chlorides. The cement powder burnt at $400{ }^{\circ} \mathrm{C}$ is characterized by greater amount of underburnt raw magnesium hydroxide which didn't react with chlorides. 
Consequently, the lowest percentage of magnesium chloride hydroxides was synthesized while hardening, which led to the minimum total deformations.

However, in spite of low level of deformation variation, cement powders with excessively high activity are not suitable for building materials production because of their tendency to cracking.

The optimum region for obtaining cements with controlled deformations is within the temperature range between 700 and $900{ }^{\circ} \mathrm{C}$. In hardened magnesium cement paste based on such powders, the processes of magnesium chloride hydroxide crystallization compensate for the initial shrinkage and stabilize within two weeks. The final phase composition of such hardened cement paste is represented by the greatest amount of magnesium chloride pentahydroxide which has the highest strength.

\section{Conclusion}

1.Based on the outcomes of the research the connection was determined between the activity of magnesium oxide powder and the behavior of deformations occurring in magnesium oxychloride cement at early age.

2. The results demonstrate the capability of producing cements with required deformations while hardening and describe the method to avoid degradation of products and structures by managing the activity of magnesium oxide powder at the stage of burning source magnesium material.

3. In order to develop mathematical models for interrelation between magnesium oxide powder activity and deformations occurring in magnesium oxychloride cement paste while hardening, it is required to perform a detailed investigation of phase composition of hardened magnesium cement paste at each of the specified hardening stages and to define the size of magnesium oxide crystals typical for every stage of powders activity.

The work was supported by Act 211 Government of the Russian Federation, contract № 02.A03.21.0011.

\section{References}

1. H. Biliuski, B. Matcovic, C. Mazuranic, Zumic Amer. Ceram. Soc. 67, 266-9 (1984)

2. I. Nanazashvili, Stroitel'nye materialy iz drevesno-cementnoj kompozicii [Building materials from wood-cement compositions] (Stroiizdat, Moscow, 1990) (in Russian)

3. A. Yanshina, Ogneupory [Refractory Materials] 11, 505-15 (1960) (in Russian)

4. B. Matcovic, S. Popovic, V. Rogic, Zunic Amer. Ceram. Soc. 60, 504-7 (1977)

5. V. Chumak, Stroitel'nye materialy [Building Materials] 9, 10-11 (2003) (in Russian)

6. V. Rogic, B. Matkovic, Cement (Zagreb) 16, 61-9 (1972)

7. C. Sims, Industrial minerals 2, 43-8 (1987)

8. X. Zhang, H. Wang, R. Chen, Construction and Building Materials 150, 409-17 (2017)

9. G. Bergman, I. Vyrodov, RJAC 3, 119-24 (1958) (in Russian)

10. G. Bergman, I. Vyrodov, RJAC 32, 504-9 (1959) (in Russian)

11. V. Vorobiev, V. Kolokolnikov, Proizvodstvo mineral'nyh vjazhushhih [Manufacture of mineral binders] (Gosstroizdat, Moscow, 1960) (in Russian)

12. I. Vyrodov, RJAC 33, 2399-404 (1960)

13. M. Mayska, D. Jindrich, Ceramics-Silikaty 41, 121-23 (1997)

14. G. Averina, T. Chernykh, L. Kramar, Proceedings of the XIII International Conference "Trends in the Development of Science and Education 4, 5-7 (2016) (in Russian) 
15. G. Averina, T. Chernykh, L. Kramar, B. Trofimov, AIP Conference Proceedings 1800, $020003(2017)$

16. GOST 1216-87. Poroshki magnezitovye kausticheskie. Tehnicheskie uslovija [Magnesite caustic powders. Specifications] (2004) (in Russian)

17. D. Beruto , R. Vecchiattini, M. Giordani, Thermochimica Acta 10, 25-33 (2003)

18. W. Noll, Angew. Chem. 62, 567-72 (1950)

19. R. Haul, H. Heystek, Am. Mineralogist 1, 166-179 (1952)

20. J. Hedvall, Anorg .allg. Chem 4, 22-25(1953)

21. GOST 24544-81. Betony. Metody opredelenija deformacij usadki i polzuchesti [Concretes. Methods of shrinkage and creep flow determination] (1987) (in Russian)

22. DIN 52450. Testing of inorganic non-metallic building materials; determination of shrinkage and expansion on small specimens (German Institute for Standardization, 1985)

23. TU 5744-001-60779432-2009 Magnezial'noe vjazhushhee stroitel'nogo naznachenija. Tehnicheskie uslovija [Magnesium oxychloride cements for construction purposes. Specifications] (2009) (in Russian) 